\title{
Hannaella luteola
}

National Cancer Institute

\section{Source}

National Cancer Institute. Hannaella luteola. NCI Thesaurus. Code C127716.

A species of fungi in the phylum Basidiomycota. This species is positive for assimilation of arabinose, sucrose, maltose, galactose, and others. It is generally non-fermenting. 